Article

\title{
Impact of Chitosan, Sucrose, Glucose, and Fructose on the Postharvest Decay, Quality, Enzyme Activity, and Defense-Related Gene Expression of Strawberries
}

\author{
Yuanhua Wang ${ }^{1,2}$, Zhiming Yan ${ }^{1,2}$, Weihua Tang ${ }^{1}$, Qing Zhang ${ }^{1}$, Bei Lu ${ }^{2}$, Qiong Li $^{1}$ and Geng Zhang ${ }^{1,2, *}$ \\ 1 Department of Agronomy and Horticulture, Jiangsu Vocational College of Agriculture and Forestry, \\ Jurong 212400, China; wangyuanhua@jsafc.edu.cn (Y.W.); yanzhim@jsafc.edu.cn (Z.Y.); \\ weihuatang@jsafc.edu.cn (W.T.); zhangqing@jsafc.edu.cn (Q.Z.); liqiongJonesHu@163.com (Q.L.) \\ 2 Engineering and Technical Center for Modern Horticulture, Jiangsu Vocational College of Agriculture and \\ Forestry, Jurong 212400, China; yzulubei@163.com \\ * Correspondence: gengzhang@jsafc.edu.cn
}

check for updates

Citation: Wang, Y.; Yan, Z.; Tang, W.; Zhang, Q.; Lu, B.; Li, Q.; Zhang, G. Impact of Chitosan, Sucrose, Glucose, and Fructose on the Postharvest Decay, Quality, Enzyme Activity, and Defense-Related Gene Expression of Strawberries. Horticulturae 2021, 7, 518. https://doi.org/10.3390/ horticulturae7120518

Academic Editor: Carmit Ziv

Received: 25 October 2021

Accepted: 22 November 2021

Published: 24 November 2021

Publisher's Note: MDPI stays neutral with regard to jurisdictional claims in published maps and institutional affiliations.

Copyright: (C) 2021 by the authors. Licensee MDPI, Basel, Switzerland. This article is an open access article distributed under the terms and conditions of the Creative Commons Attribution (CC BY) license (https:// creativecommons.org/licenses/by/ $4.0 /)$

\begin{abstract}
Strawberry is one of the most highly consumed fruits worldwide, but is extremely perishable. This study systematically compared the effects of chitosan, sucrose, glucose, and fructose immersion on the physiology and disease development in harvested strawberries. After storage at $15{ }^{\circ} \mathrm{C}$ for 9 days, all sugar treatment groups had significantly higher total soluble solids and total anthocyanin content than those of the control group. All sugar treatment groups inhibited malondialdehyde accumulation. At the end of the storage, chitosan, glucose, and fructose maintained higher superoxide dismutase activity and chitosan maintained higher catalase activity. The chitosan and glucose groups had lowest fruit decay index, followed by sucrose and fructose groups. The fruit firmness and luster were better maintained in the glucose group. Furthermore, genes related to sucrose metabolism (e.g., FaSUS1 and FaSUS2), titratable acidity accumulation (e.g., FaMDH1, FaMDH2, $F a C S 1$, and $F a C S 2$ ), disease resistance (e.g., FaPGIP1, FaWRKY1, and FaWRKY33) and to anabolic jasmonic acid and abscisic acid pathways (e.g., FaJAZ1, FaJAZ2, FaOPR3, FaNCED1, and FaNCED2) were regulated to varying degrees, suggesting that chitosan and glucose participate in plants' immune signaling networks and regulate disease resistance in fruit through hormone pathways. The findings provide new insights into the physiological regulation of harvested strawberries.
\end{abstract}

Keywords: Fragaria $\times$ ananassa; chitosan; sucrose; glucose; fructose; postharvest

\section{Introduction}

The cultivated strawberry (Fragaria $\times$ ananassa Duch.), known as the "Queen of Fruits," has both nutritional and ornamental value. Vibrant in color, full-bodied in flavor, and rich in nutrition, strawberries are favored by producers and consumers alike [1,2]. However, because of their soft flesh and extremely thin outer layer, strawberries spoil easily and are highly susceptible to mechanical damage and pathogenic infection, all of which cause great losses to strawberry production [3,4]. To slow the decay rate of harvested strawberries and maximize their shelf life, scholars have conducted a substantial amount of research on strawberries' ripening and senescence mechanisms as well as the diseases to which harvested strawberries are susceptible, and favorable storage strategies [5,6].

Botrytis cinerea, Rhizopus stolonifer, and Colletotrichum gloeosporioides are the principal fungi that cause fruit rot in strawberries, leading to low strawberry yield and quality [7-9]. Chemical fungicides have long been considered the most effective means of preventing and controlling decay in harvested strawberries [10]. The unscientific use of these agents has various drawbacks, including environmental pollution (e.g., in the form of residues) and pathogen resistance-related decline in the effectiveness of control. As the global standard of living has risen, accompanied by changes in the concept of consumption, people have devoted significant attention to the environment and to its effect on their health $[11,12]$. This 
partially explains why chemical fungicide administration is no longer the ideal approach to preventing rot in harvested strawberries. Thus, exploration of pollution-free postharvest decay control strategies is warranted for facilitating the development of the strawberry industry, including with respect to enhancing fruit quality and improving preservation efficiency. Over the past decade, numerous methods have been proposed for prolonging the shelf life of strawberries, including cold storage [13], ozone treatment [14], heat treatment [15], biological control [16], edible coating [17], and bioactive compounds [4,18]. Edible coating is a particular topic of interest because they are regarded as an efficient, safe means of preserving strawberries' freshness. Their advantages include the fact that they are environmentally benign, leave no residue, and are not susceptible to drug resistance.

Chitosan, the only naturally occurring alkaline polysaccharide, is a biodegradable macromolecule [19]. It has excellent application prospects in agricultural production by virtue of its nontoxicity, low price, and high efficiency among other advantages [20]. Exogenous chitosan treatment increases the antioxidant capacity of harvested fruits (e.g., blueberries, strawberries, and kiwis), helping to maintain their quality. Soluble sugars (e.g., sucrose, glucose, and fructose) are responsible for the sensory quality of fruits and vegetables, and pivotally affect changes in the physiological, biochemical, and nutritional quality of fresh produce. In plants, soluble sugars are involved in various metabolic processes as essential energy sources and osmotic adjustment substances. Virgen-Ortiz et al. [21] reported that a pectin oligosaccharide coating not only delayed loss of firmness and water content in strawberries but also increased anthocyanin and antioxidant activity, improving the overall quality of the fruit. Chitosan treatment is favorable for preserving freshness in strawberries, modulating their physiological metabolism and inhibiting microbial infestation [22]. Exogenous sucrose can be used as a carbon source for broccoli to maintain a high respiration rate and delay chlorophyll degradation [23]. In a similar vein, treatment of harvested kiwis with exogenous sucrose promoted ripening by regulating the ethylene pathway [24]. Sucrose plays a role, as a signal molecule, in regulating plant growth and development. Fructose, glucose, and other soluble sugars regulate the quality and physiological senescence of fruits and vegetables through sucrose metabolism. Moreover, these soluble sugars interact with phenolics to establish reducing conditions, eliminate free radicals, and improve the stress resistance of cells and tissues. In most of the relevant evidence, emphasis is placed on the physiological and biochemical effects of sugars on harvested fruits and vegetables (e.g., with respect to respiration, antioxidant capacity, and quality) as well as on the growth of pathogenic microorganisms. However, little work has been done to clarify the mechanism through which sugars control diseases in harvested strawberries, especially by systematic comparison. In particular, investigations into the effects of various types of sugar on quality deterioration and disease development in harvested strawberries have been rare.

In this study, harvested strawberries $(F . \times$ ananassa $D ., \mathrm{cv}$. Benihoppe) were used as the experimental material. They were treated with four inexpensive, environmentally benign preservatives, namely chitosan, fructose, glucose, and sucrose, and their individual effects on fruit quality and disease development were examined. First, the effects of various types and concentrations of sugar on the strawberries' decay index and commodity rate were investigated, and the optimal concentrations of preservatives were preliminarily determined. Subsequently, the sugars' effects on the strawberries' firmness, decay index, quality, and antioxidant enzyme activity at each optimal concentration were compared. Furthermore, the mechanisms through which the sugars regulated quality changes and disease development in the fruits were assessed by analyzing the expression of some genes related to fruit disease and preservation. The findings are conducive to the development of green, inexpensive, and efficient strawberry preservatives. Moreover, they guide understanding of the contribution of sugars to the maintenance of physiological quality and the prevention of disease in harvested strawberries. As such, this study serves as both a theoretical and practical reference. 


\section{Materials and Methods}

\subsection{Plant Materials}

Strawberries were harvested from strawberry fields in the Jiangsu Agricultural Expo Park located in Jurong, Jiangsu Province, China. The fruits were required to be uniform in size; be free from deformity, disease, pests, and mechanical damage; and have uniform ripeness $(75-80 \%)$. Immediately after being harvested, the fruits were transported to the laboratory, and their surfaces were cleaned with distilled water before treatment.

\subsection{Experimental Design}

The appropriate concentration of sugar solution to use for strawberry preservation depends on the type of sugar. The control group comprised strawberries immersed in distilled water. In the treatment groups, the strawberries were immersed in sugar solutions of varying concentrations: chitosan $(1,3,5$, and $7 \mathrm{~g} / \mathrm{L})$, sucrose $(1,3,5$, and $7 \mathrm{~g} / \mathrm{L})$, glucose $(5,10,15$, and $20 \mathrm{~g} / \mathrm{L})$, or fructose $(5,10,15$, and $20 \mathrm{~g} / \mathrm{L})$. Specifically, the fruits were dipped in the solution for $20 \mathrm{~s}$, and fresh solution was used for each strawberry. Next, the treated strawberries were placed on an ultraclean workbench and dried using sterile wind. Thereafter, they were placed in a stainless steel tray lined with filter paper, which was covered with plastic cling film for moisture preservation, and the tray was stored in an incubator with a relative humidity of $90 \% \pm 5 \%$ at $15 \pm 2{ }^{\circ} \mathrm{C}$ for 11 days (Figure 1 ). Disease incidence was recorded by taking daily photographs of the fruits, and the decay index was determined. The experiment was performed three times, with 150 fruits treated each time.

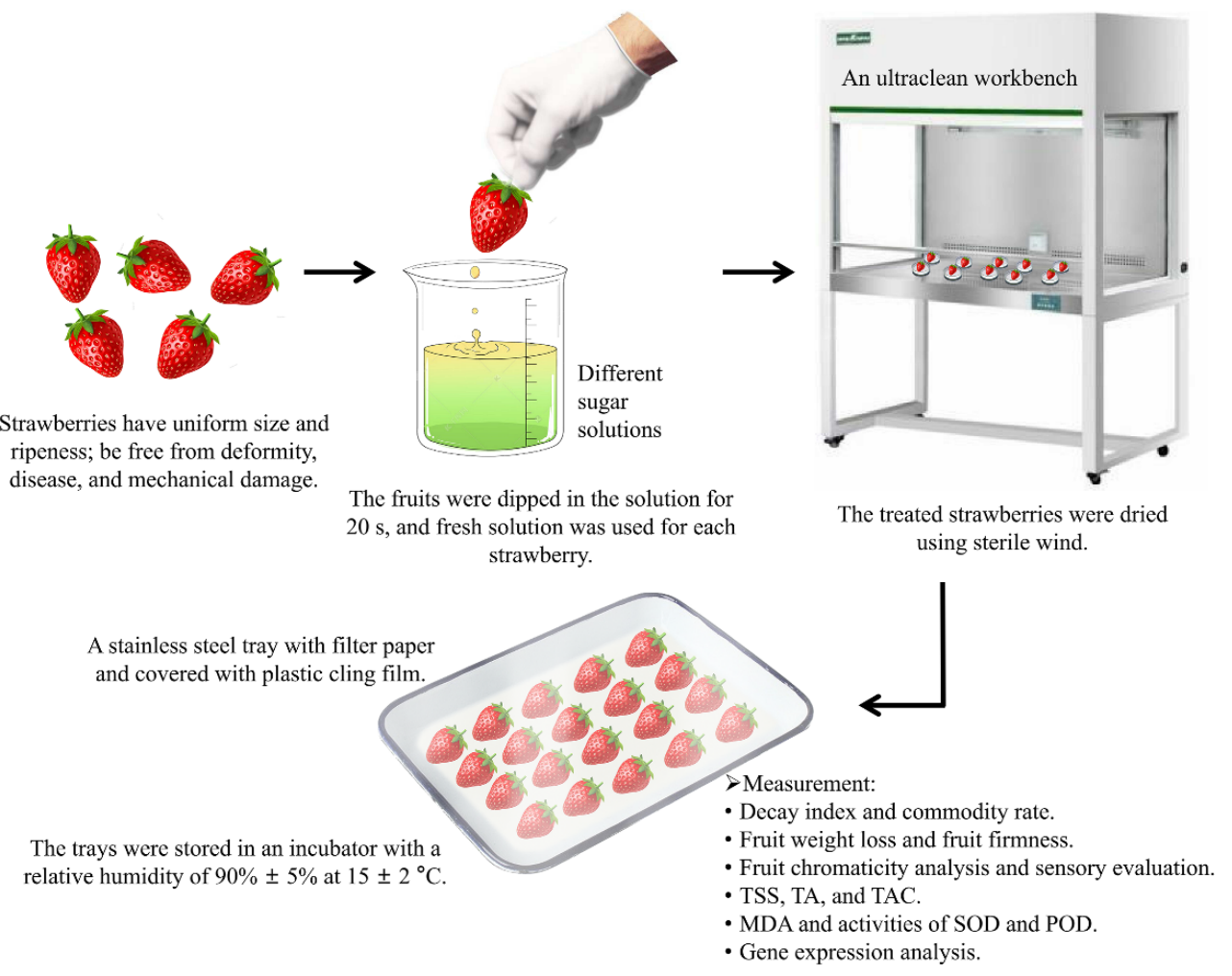

Figure 1. Experimental process flow chart. TSS, total soluble solids; TA, titratable acidity; TAC, total anthocyanin content; MDA, malondialdehyde; SOD, superoxide dismutase; CAT, catalase.

According to the results of the sugar concentration screening experiment, the appropriate concentration of various sugar solutions was determined for subsequent tests. Strawberries were immersed in $3 \mathrm{~g} / \mathrm{L}$ chitosan, $5 \mathrm{~g} / \mathrm{L}$ sucrose, $15 \mathrm{~g} / \mathrm{L}$ glucose, or $15 \mathrm{~g} / \mathrm{L}$ fructose, following the same method used in the screening experiment. The control group contained strawberries treated with distilled water. The treated fruits were stored in an incubator with a relative humidity of $90 \% \pm 5 \%$ at $15 \pm 2{ }^{\circ} \mathrm{C}$ for 9 days. As in the screening 
experiment, disease incidence was recorded by taking daily photographs of the strawberries, and the decay index, commodity rate, and weight loss were documented. Every other day, the quality index, physical and chemical index, and gene expression levels of the fruits were determined. The experiment was performed three times, with 150 fruits treated each time.

\subsection{Analytical Methods}

\subsubsection{Evaluation of Decay Index and Commodity Rate}

Following the methods of Molinett et al. [25] and Hu et al. [26] with some modifications, we classified the strawberries' decay index into five grades in accordance with the decay area (Figure 2). The grades are as follows.

(1) Grade 0: fruit surface free from decay and disease spots, brightly colored calyx and stalk, and no wilting; (2) Grade 1: no clear decay on the fruit surface, dull-colored calyx and stalk, and obvious wilting; (3) Grade 2: slightly decayed fruit surface, with the decayed area accounting for less than $10 \%$ of the total fruit area; dull-colored calyx and stalk; and obvious wilting; (4) Grade 3: clearly decayed fruit surface, with the decayed area accounting for $10 \%$ to $40 \%$ of the total fruit area; dull-colored calyx and stalk; and obvious wilting; (5) Grade 4: severely decayed fruit surface, with the decayed area accounting for more than $40 \%$ of the total fruit area; dull-colored calyx and stalk; and severe wilting. For each treatment, the decay assessment was performed every other day by using the entire sample of 50 fruits, and the experiment was performed three times.

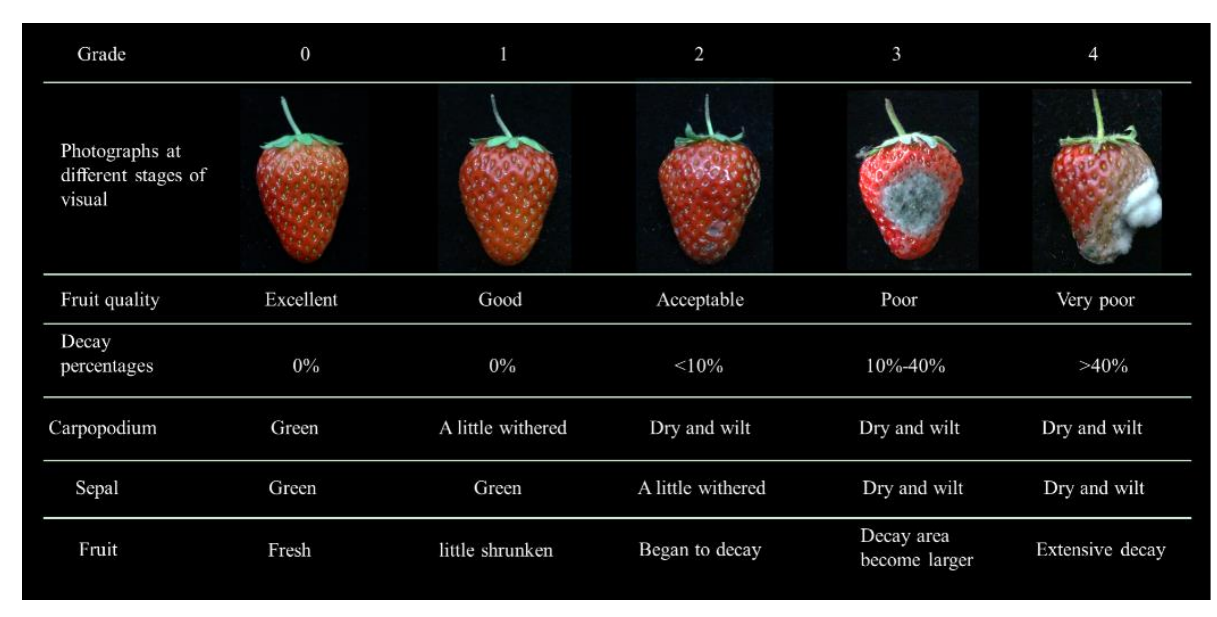

Figure 2. Incidence grade and descriptor for strawberry (Fragaria $\times$ ananassa Duch.) fruit.

The decay index was calculated using the following equation:

Decay index $=\left[\sum(\right.$ decay grade $\times$ number of fruits per grade $) /($ highest decay grade $\times$ total number of fruits) $] \times 100 \%$

The strawberries without decay, as well as those with a low grade of decay (i.e., Grade 1), were defined as being fit for sale. The commodity rate was calculated using the following equation:

Commodity rate $=($ number of fruits with Grade 0 decay + number of fruits with Grade 1 decay)/total number of fruits $\times 100 \%$ 


\subsubsection{Measurement of Weight Loss}

Fruit weight loss was calculated using the equation presented by Hernández-Muñoz et al. [27]:

Weight loss $(\%)=[$ (weight of fruit before storage - weight of fruit after storage intervals)/weight of fruit before storage $] \times 100$

\subsubsection{Fruit Firmness Measurement}

By employing the method proposed by Nguyen et al. [28], the firmness of the strawberries at the equatorial part was examined using a penetrometer, specifically the Digital Fruit Hardness Tester (GY-4, TUOKE Instruments Co., Ltd., Qingdao, China). The firmness level was defined as the maximum penetration force reached during tissue breakage, with results expressed as Newtons per square centimeter.

\subsubsection{Fruit Chromaticity Analysis}

The color and luster of individual fruits was analyzed using a spectrophotometer (TS7036, 3nh Technology Co., Ltd., Shenzhen, China), which was set up with D65 illuminat [21]. Specifically, the $a^{*}$ and $L^{*}$ values were determined. The $a^{*}$ value represents chromaticity on a green to red axis, and the $\mathrm{L}^{*}$ value represents black and white or dark and light [25], details in Figure S1. Two measurements on each equatorial side were performed for each strawberry.

\subsubsection{Sensory Evaluation}

On day 9 of storage, the strawberries were given sensory scores using the method described by Lu et al. [29], with some modifications. In brief, 20 panelists (10 men and 10 women, aged 20 to 30 years) with normal color vision and olfactory ability were selected for training. A total of 150 strawberries in each treatment group were evaluated and scored on five dimensions (each of which was awarded a score from 1 to 5): color, aroma, water-soaked spots, disease spots, and firmness (Table S1). The test was conducted under white light, and the comprehensive score of each dimension was the average score awarded by the 20 panelists.

2.3.6. Determination of Total Soluble Solids (TSS), Titratable Acidity (TA), and Total Anthocyanin Content (TAC)

The TSS in the pulp of the treated strawberries was determined using a PAL-1 portable sugar meter with a digital display (Atago Co., Ltd., Saitama, Japan). The TA of the strawberries was determined using the method described by Vieira et al. [30]. The TAC was measured using the $\mathrm{pH}$ differential method employed by Xing et al. [31].

2.3.7. Determination of Malondialdehyde (MDA) Content and Activities of Superoxide Dismutase and Catalase

The MDA concentrations of the treated fruits were estimated using the method of Heath et al. [32]. The activities of superoxide dismutase (SOD; EC: 1.15.1.1) and catalase (CAT; EC: 1.11.1.6) in the strawberry pulp were assessed using the method of Zhang et al. [33]. Protein content was determined through the approach of Bradford [34]. Fresh strawberry samples $(0.1 \mathrm{~g})$ were homogenizing with $1 \mathrm{~mL}$ phosphate buffer, and the mixtures were centrifuged at $4000 \times g$ for $15 \mathrm{~min}$ at $4{ }^{\circ} \mathrm{C}$. The supernatant was quantified for protein at $595 \mathrm{~nm}$. Enzyme activity is expressed in units per milligram of protein.

\subsubsection{Analysis of Gene Expression}

The treated strawberries were frozen with liquid nitrogen and stored at $-80^{\circ} \mathrm{C}$ before gene expression detection. A total of 23 genes related to the senescence (abscisic acid [ABA] and jasmonic acid [JA] pathways), quality (softening, sweetness, acidity, and aroma), and disease resistance of strawberries were selected. FaActin was selected as the internal control. The relative expression levels of all genes were calculated using the $2^{-\Delta \Delta \mathrm{Ct}}$ 
method. The experiment was performed three times. Primers used for the quantitative reverse transcription polymerase chain reaction analysis (qRT-PCR) are listed in Table S2.

\subsection{Statistical Analysis}

All data are presented as the means \pm standard errors (SEs) of the three replications of each treatment. One-way analysis of variance was conducted with Tukey's HSD test by using SPSS Statistics, version 18.0 (SPSS Inc., Chicago, IL, USA). The level of significance was set at $5 \%$.

\section{Results}

\subsection{Sugar Solution Concentration Screening Experiment}

To compare the effects of the various sugars on the quality of and disease development in harvested strawberries, a screening experiment of sugar concentration was first conducted. As presented in Figure 3, immersion in various concentrations of sugar solution had clear effects on the appearance quality and the decay index of the strawberries in storage. In the control group, the disease spots began to appear on the surface of the strawberries on day 3 , and after 5 days, the degrees of softening and decay were significantly greater, as was the decayed area (Figure 3A). Immersion in the four types of sugar solution exerted differing inhibition effects on softening, decay, and the spread of disease spots. Notably, treatment with $3 \mathrm{~g} / \mathrm{L}$ chitosan, $5 \mathrm{~g} / \mathrm{L}$ sucrose, $15 \mathrm{~g} / \mathrm{L}$ glucose, or $15 \mathrm{~g} / \mathrm{L}$ fructose clearly delayed the softening of the strawberries on day 11 (Figure 3A). The decay index of the strawberries in control group increased gradually over time, whereas the degree of decay was maintained lower in four types of sugar solution treatment (Figure 3B). After 11 days in storage, the decay index of the strawberries in the four treatment with $3 \mathrm{~g} / \mathrm{L}$ chitosan, $5 \mathrm{~g} / \mathrm{L}$ sucrose, $15 \mathrm{~g} / \mathrm{L}$ glucose, or $15 \mathrm{~g} / \mathrm{L}$ fructose was generally low (Figure 3B), with most fruits maintaining favorable color and aroma. At this point, the strawberries still had high commercial value. Therefore, the groups treated with $3 \mathrm{~g} / \mathrm{L}$ chitosan, $5 \mathrm{~g} / \mathrm{L}$ sucrose, $15 \mathrm{~g} / \mathrm{L}$ glucose, and $15 \mathrm{~g} / \mathrm{L}$ fructose (hereafter the chitosan, sucrose, glucose, and fructose groups) were subjected to subsequent experiments.

\subsection{Effects of Treatment on Decay Index and Commodity Rate}

As shown in Figure 4A, the decay index of the treatment groups was significantly lower than that of the control group. Furthermore, significant differences were detected in the decay index among the individual treatment groups. The chitosan and glucose groups had the lowest fruit decay index $(27.0 \%$ and $31.0 \%$, respectively). These two treatments exerted a stronger inhibitory effect against decay; this is beneficial to fruit storage. The fruit decay indexes of the sucrose and fructose groups $(55.0 \%$ and $63.0 \%$, respectively) was higher than those of the chitosan and glucose groups. These sucrose and fructose treatments had the second-strongest inhibitory effects against fruit decay during storage. The strawberries in all treatment groups had a significantly lower decay index than did those in the control group, indicating that sugar solution treatment was effective in reducing the fruits' decay index.

Immersion in sugar solutions can significantly improve the commodity rate of strawberries (Figure 4B). After storage at $15{ }^{\circ} \mathrm{C}$ for 9 days, the commodity rate of the control group was only $21.4 \%$, whereas that of the treatment groups had remained relatively high. The commodity rates of the chitosan, sucrose, glucose, and fructose groups were $73.8 \%$, $51.4 \%, 68.9 \%$, and $60.3 \%$, respectively. Significant differences in the commodity rate were noted between sugar treatment groups and control group. The commodity rate in the chitosan and glucose groups were significantly higher than those in the sucrose and fructose groups. The commodity rate in the sucrose group was significantly lower than that in the fructose group. No significant difference in commodity rate was observed between the chitosan and glucose groups. This indicates that differing sugar treatments have distinct positive effects on strawberries' commodity rate, with chitosan and glucose having the optimal effect. 
(A)

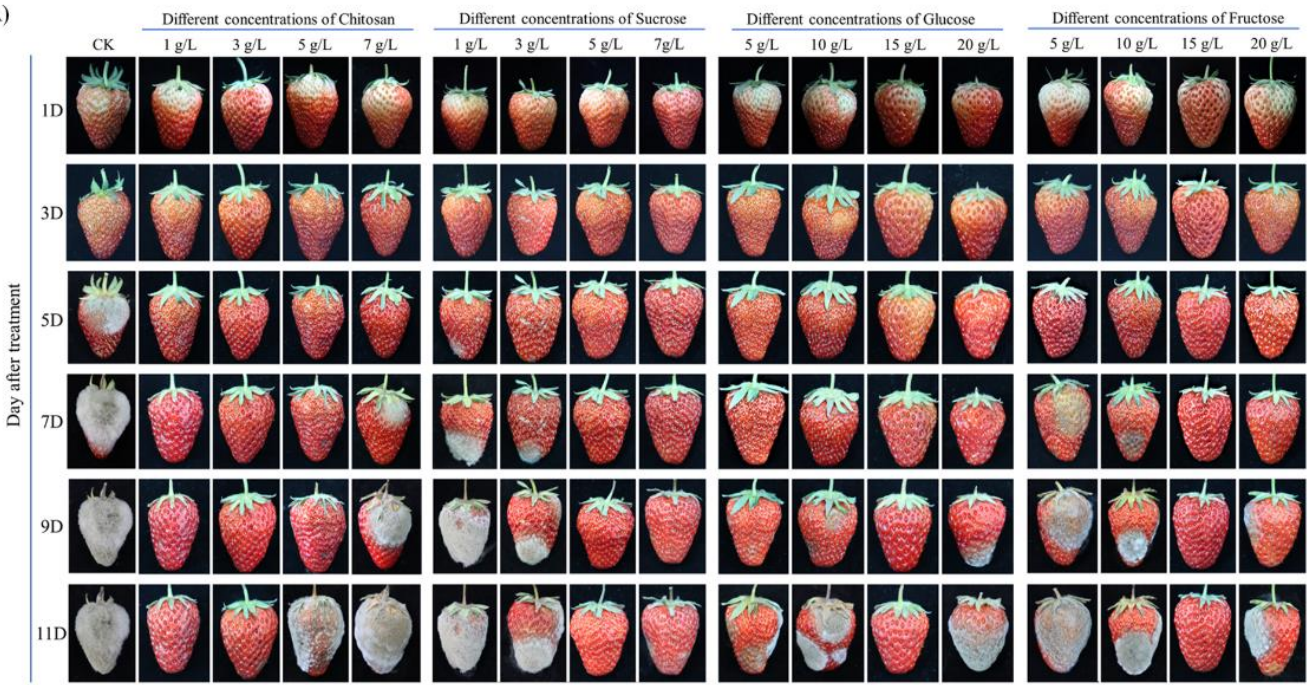

(B)

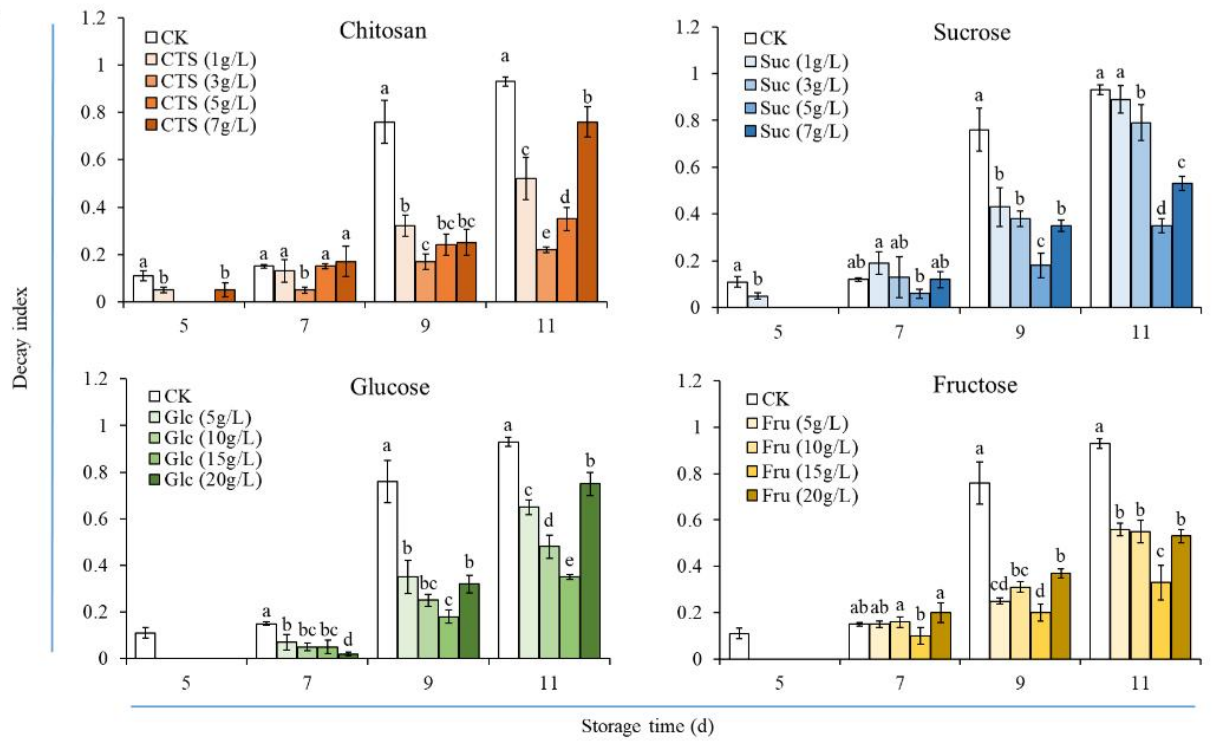

Figure 3. Effects of different sugar treatments on the (A) visual quality and (B) decay index of strawberry fruits stored at $15 \pm 2{ }^{\circ} \mathrm{C}$ for $11 \mathrm{~d}$. Data are mean of three replicates. Different letters on top of bars in the same storage time indicate a significant difference (Tukey's HSD test, $p<0.05$ ). CK represents that strawberry fruits were immersed with water before storage; $1,3,5,7 \mathrm{~g} / \mathrm{L}$ CTS represents that strawberry fruits were immersed with 1, 3, 5, $7 \mathrm{~g} / \mathrm{L}$ chitosan before storage, respectively; 1, 3, 5, $7 \mathrm{~g} / \mathrm{L}$ Suc represents that strawberry fruits were immersed with 1, 3, 5, $7 \mathrm{~g} / \mathrm{L}$ sucrose before storage, respectively; 5, 10, 15, $20 \mathrm{~g} / \mathrm{L}$ Glc represents that strawberry fruits were immersed with 5, 10, 15, $20 \mathrm{~g} / \mathrm{L}$ glucose before storage, respectively; 5, 10, 15, $20 \mathrm{~g} / \mathrm{L}$ Fru represents that strawberry fruits were immersed with $5,10,15,20 \mathrm{~g} / \mathrm{L}$ fructose before storage, respectively; the same below.

\subsection{Effects of Treatments on Firmness, Weight Loss, and Color after Storage}

As displayed in Table 1, the firmness of strawberries in all groups decreased over time, but the sugar treatments prevented the exacerbation of this decline to a certain extent. After storage at $15^{\circ} \mathrm{C}$ for 9 days, the firmness of the strawberries in the chitosan, sucrose, and glucose groups was higher than that of those in the control group-specifically, 1.10, 1.13 , and 1.23 times higher, respectively. Immersion in $15 \mathrm{~g} / \mathrm{L}$ glucose solution exerted the optimal effect on alleviating the drop in firmness, the value was significantly higher than that of the control group. No significant difference in firmness was observed between the chitosan, sucrose, fructose, and control groups. 

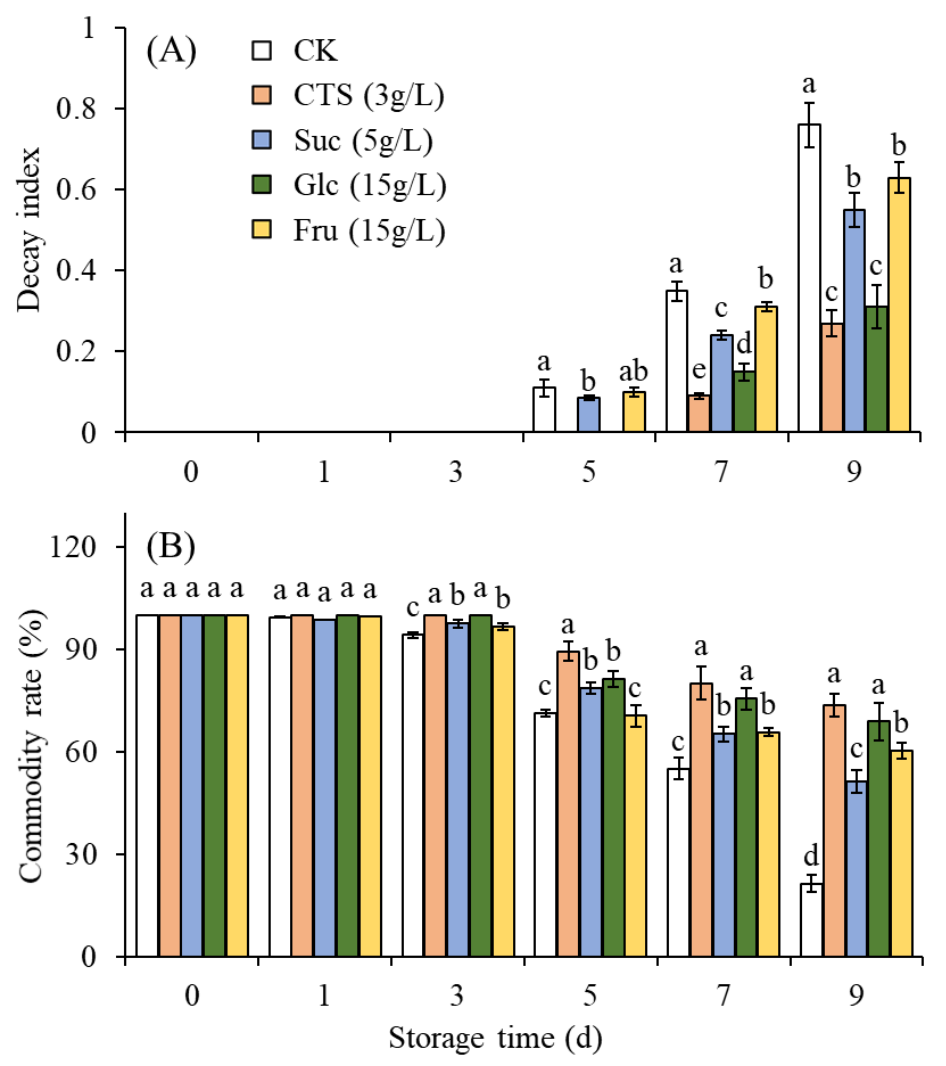

Figure 4. Effects of chitosan ( $3 \mathrm{~g} / \mathrm{L})$, sucrose $(5 \mathrm{~g} / \mathrm{L})$, glucose $(15 \mathrm{~g} / \mathrm{L})$, and fructose $(15 \mathrm{~g} / \mathrm{L})$ on the (A) decay index and (B) commodity rate of strawberry fruits stored at $15 \pm 2{ }^{\circ} \mathrm{C}$ for $9 \mathrm{~d}$. CK represents that strawberry fruits were immersed with water before storage. Data are mean of three replicates. Different letters on top of bars in the same storage time indicate a significant difference (Tukey's HSD test, $p<0.05)$. CTS, chitosan; Suc, sucrose; Glc, glucose; Fru, fructose.

The loss of water in fruit, which leads to a decline in quality, can be characterized by weight loss. As presented in Table 1, over time, the weight loss of the control and treatment groups increased to varying degrees. The weight loss of the control group was $19.51 \%$ after storage for 9 days at $15{ }^{\circ} \mathrm{C}$, whereas that of the chitosan and fructose groups was significantly lower. Overall, the weight loss of the strawberries in the chitosan, sucrose, glucose, and fructose groups after storage for 9 days at $15^{\circ} \mathrm{C}$ was $9.51 \%, 17.15 \%, 18.74 \%$, and $14.62 \%$, respectively.

Over time, the strawberries ripened gradually, and the $\mathrm{a}^{*}$ values of both the control and treatment groups increased considerably (Table 1). After 9 days of storage at $15^{\circ} \mathrm{C}$, no significant difference between the sugar treatment groups and control group for the $\mathrm{a}^{*}$ values of the strawberries (Table 1). This indicated that immersion in chitosan, sucrose, glucose, or fructose solution had no clear effect on fruit color. After 9 days of storage at $15^{\circ} \mathrm{C}$, the $\mathrm{L}^{*}$ values of the strawberries in all groups were drastically decreased, but that of the glucose group was significantly higher than that of the control group (Table 1). This indicated that fruit luster was better maintained when the fruits were immersed in glucose solution. 
Table 1. Effects of chitosan ( $3 \mathrm{~g} / \mathrm{L})$, sucrose $(5 \mathrm{~g} / \mathrm{L})$, glucose $(15 \mathrm{~g} / \mathrm{L})$, and fructose $(15 \mathrm{~g} / \mathrm{L})$ on the firmness, weight loss, $\mathrm{a}^{*}$ value, and $\mathrm{L}^{*}$ value of strawberry fruits stored at $15 \pm 2{ }^{\circ} \mathrm{C}$ for 0 and $9 \mathrm{~d}$.

\begin{tabular}{cccccc}
\hline Storage Time (d) & Treatment & Firmness (N) & Weight Loss (\%) & a* Value $^{*}$ & L Value $^{*}$ \\
\hline & CK & $4.49 \pm 0.09 \mathrm{a}$ & - & $25.51 \pm 1.25 \mathrm{a}$ & $53.83 \pm 4.05 \mathrm{a}$ \\
& CTS (3 g/L) & $4.51 \pm 0.54 \mathrm{a}$ & - & $25.58 \pm 2.95 \mathrm{a}$ & $53.01 \pm 4.81 \mathrm{a}$ \\
0 & Suc (5 g/L) & $4.55 \pm 0.31 \mathrm{a}$ & - & $24.85 \pm 3.64 \mathrm{a}$ & $54.95 \pm 3.21 \mathrm{a}$ \\
& Glc (15 g/L) & $4.46 \pm 0.50 \mathrm{a}$ & - & $25.74 \pm 5.64 \mathrm{a}$ & $53.19 \pm 4.01 \mathrm{a}$ \\
& Fru (15 g/L) & $4.54 \pm 0.49 \mathrm{a}$ & - & $25.52 \pm 3.77 \mathrm{a}$ & $53.57 \pm 3.74 \mathrm{a}$ \\
\hline & CK & $2.61 \pm 0.36 \mathrm{~b}$ & $19.51 \pm 0.11 \mathrm{a}$ & $32.33 \pm 2.55 \mathrm{a}$ & $30.27 \pm 2.65 \mathrm{~b}$ \\
& CTS (3 g/L) & $2.87 \pm 0.37 \mathrm{ab}$ & $9.51 \pm 0.05 \mathrm{c}$ & $34.18 \pm 2.60 \mathrm{a}$ & $33.08 \pm 4.81 \mathrm{ab}$ \\
& Suc (5 g/L) & $2.94 \pm 0.26 \mathrm{ab}$ & $17.15 \pm 2.11 \mathrm{ab}$ & $34.67 \pm 1.87 \mathrm{a}$ & $31.56 \pm 1.69 \mathrm{~b}$ \\
& Glc (15 g/L) & $3.21 \pm 0.16 \mathrm{a}$ & $18.74 \pm 3.11 \mathrm{a}$ & $35.78 \pm 2.00 \mathrm{a}$ & $37.18 \pm 2.67 \mathrm{a}$ \\
& Fru (15 g/L) & $2.67 \pm 0.17 \mathrm{~b}$ & $14.62 \pm 0.10 \mathrm{~b}$ & $33.20 \pm 2.58 \mathrm{a}$ & $30.30 \pm 1.33 \mathrm{~b}$ \\
\hline
\end{tabular}

Data presented are the means \pm SEs $(n=3)$. Different letters in each column in the same storage time indicate significant differences (Tukey's HSD test, $p<0.05$ ). CK represents that strawberry fruits were immersed with water before storage. CTS, chitosan; Suc, sucrose; Glc, glucose; Fru, fructose. The a* value represents chromaticity on a green to red axis, and the $L^{*}$ value represents black (dark) and white (light).

\subsection{Effects of Treatments on Sensory Scores of Strawberries after Storage}

As shown in Figure 5, as the duration of storage increased, the quality of the appearance of the control strawberries decreased obviously. After storage at $15^{\circ} \mathrm{C}$ for 9 days, the control group had reduced scores in color, firmness, and aroma, and most of the fruits had clear water stains and disease spots on their surfaces. Furthermore, the sensory perceptions of these fruits were poor. Strawberries in the chitosan, sucrose, glucose, and fructose groups were firmer than those in the control group. The strawberries in the chitosan and glucose groups scored higher on color and aroma than did those in the control group. They were also less rotten. The aroma score of the strawberries in the chitosan, sucrose, and glucose groups was higher than that of those in the control group. Most strawberries in the sucrose group had large water stains and disease spots; this observation was similar to that of the control group. Similar color or aroma score were detected in the fructose and control groups. Most strawberries in the fructose group had large water stains and disease spots on their surfaces. Overall, the chitosan and glucose treatments inhibited mold growth, reduced the degree of decay, and helped preserve the color, aroma, and firmness of the strawberries.

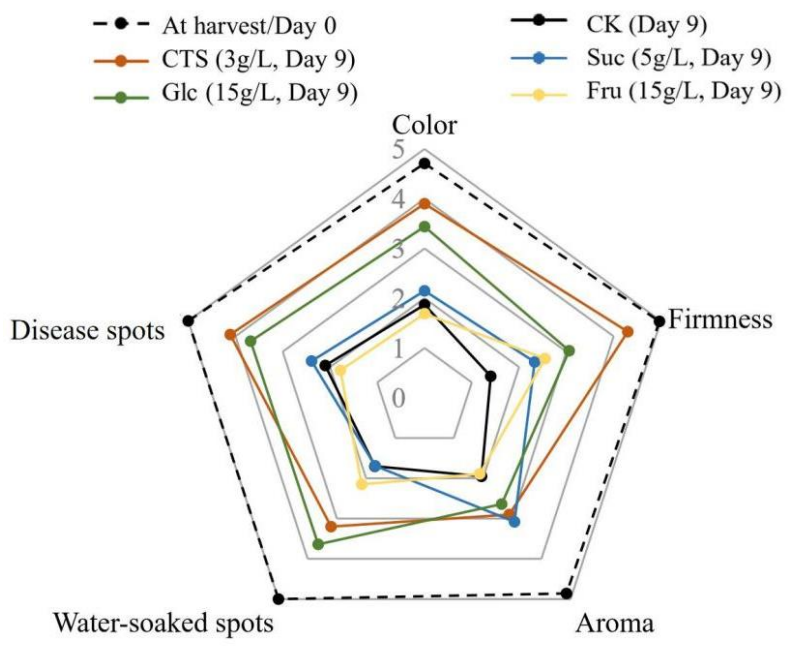

Sensory evaluation of fresh strawberry

Figure 5. Sensory evaluation of fresh strawberry fruits at the 0th day and strawberry fruits treated with $3 \mathrm{~g} / \mathrm{L}$ chitosan, $5 \mathrm{~g} / \mathrm{L}$ sucrose, $15 \mathrm{~g} / \mathrm{L}$ glucose, and $15 \mathrm{~g} / \mathrm{L}$ fructose, respectively, at the 9th day, stored at $15 \pm 2{ }^{\circ} \mathrm{C}$. CK represents that strawberry fruits were immersed with water before storage. The information about sensory indicator and standard for evaluation can be found in supplementary Table S1. Data are mean of scores given by twenty panelists. CTS, chitosan; Suc, sucrose; Glc, glucose; Fru, fructose. 


\subsection{Effects of Treatments on Total Soluble Solid (TSS), Titratable Acid (TA), and Total Anthocyanins Content (TAC)}

Over time, the TSS of the strawberries in all groups first increased and then decreased (Figure 6A). After storage at $15{ }^{\circ} \mathrm{C}$ for 9 days, the TSS of the treated strawberries was significantly higher than that of the control strawberries, with the glucose group having the highest TSS (Figure 6A). During storage, the TA of the strawberries in all groups decreased continually (Figure 6B). At the end of storage, the TA of the chitosan group was significantly higher than that of the control group (Figure $6 \mathrm{~B}$ ). With prolongation of the storage period, the TAC of the strawberries in all groups first increased and then decreased (Figure 6B). However, starting from day 3 , the TACs of the chitosan and glucose groups significantly exceeded that of the control group (Figure $6 \mathrm{C}$ ). After storage at $15^{\circ} \mathrm{C}$ for 9 days, the TAC of the strawberries in all sugar treatment groups was significantly higher than that of the control. The TAC in the chitosan and fructose groups were significantly higher than that in the sucrose groups. No significant difference in TAC was observed between the sucrose and glucose groups. (Figure 6C).

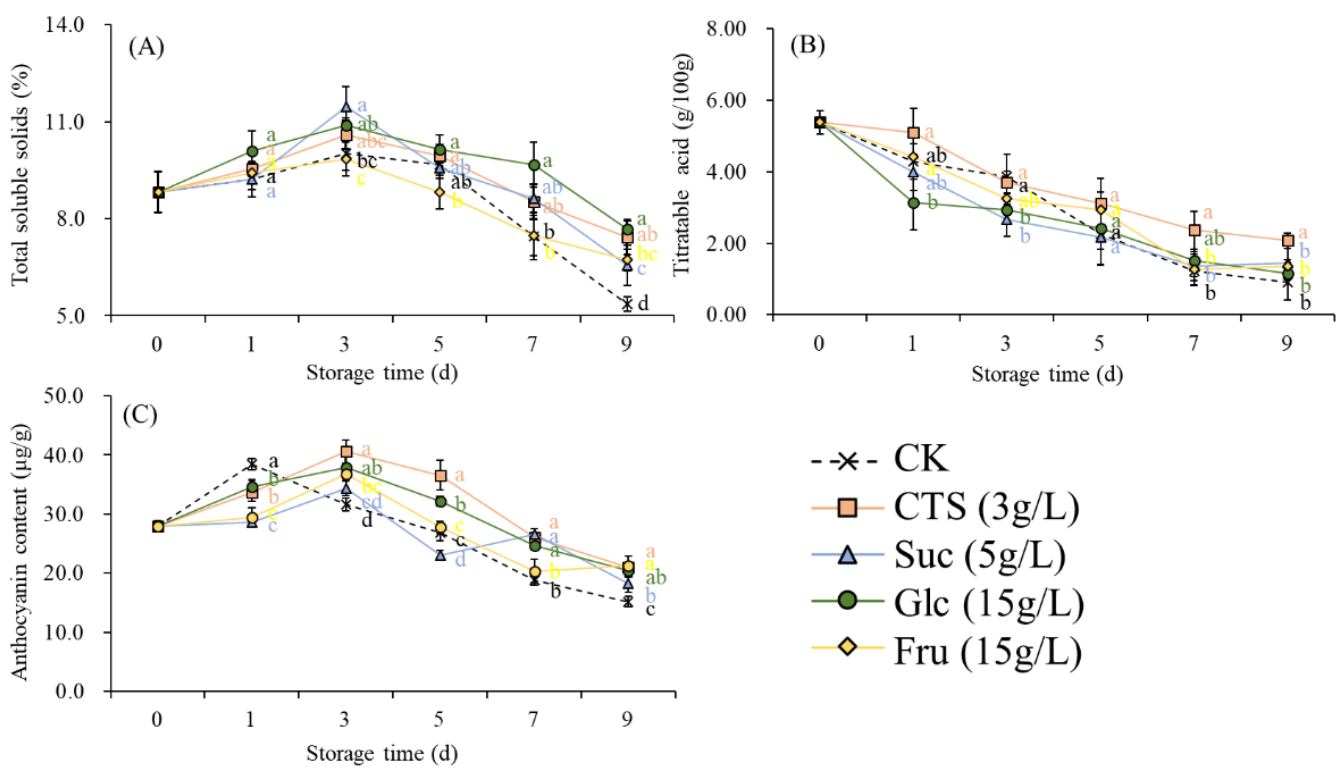

Figure 6. Effects of chitosan ( $3 \mathrm{~g} / \mathrm{L})$, sucrose $(5 \mathrm{~g} / \mathrm{L})$, glucose $(15 \mathrm{~g} / \mathrm{L})$, and fructose $(15 \mathrm{~g} / \mathrm{L})$ on the (A) titratable acid, (B) total soluble solids, and (C) total anthocyanin content of strawberry fruits stored at $15 \pm 2{ }^{\circ} \mathrm{C}$ for $9 \mathrm{~d}$. CK represents that strawberry fruits were immersed with water before storage. Data are mean of three replicates. Different letters in the same storage time indicate a significant difference (Tukey's HSD test, $p$ < 0.05). CTS, chitosan; Suc, sucrose; Glc, glucose; Fru, fructose.

\subsection{Effects of Treatments on Malondialdehyde (MDA) Content and Antioxidant Enzyme Activity}

Over time, the MDA content increased in all groups (Figure 7A). Specifically, it increased slowly in the early stage of storage and then increased rapidly starting from day 5 (Figure 7A). The MDA content of the control group peaked at the end of the storage period. However, during the late storage process, the MDA content of the treatment groups (except for fructose group at the 5th day) was significantly lower than that of the control group (Figure 7A). After storage at $15{ }^{\circ} \mathrm{C}$ for 9 days, the MDA content was significantly lower in the chitosan, sucrose, glucose, and fructose groups versus control group (Figure 7A). The SOD activity of the strawberries in all groups increased at first and then decreased during the storage (Figure 7B). After storage at $15^{\circ} \mathrm{C}$ for 9 days, the SOD activity of the chitosan, glucose, and fructose groups was significantly higher than that of the control group (Figure 7B). During storage, the CAT activity of the strawberries in all groups first increased and then decreased (Figure 7C). After storage at $15^{\circ} \mathrm{C}$ for 9 days, the CAT activity of the chitosan group was significantly higher than that of the control group (Figure 7C). 

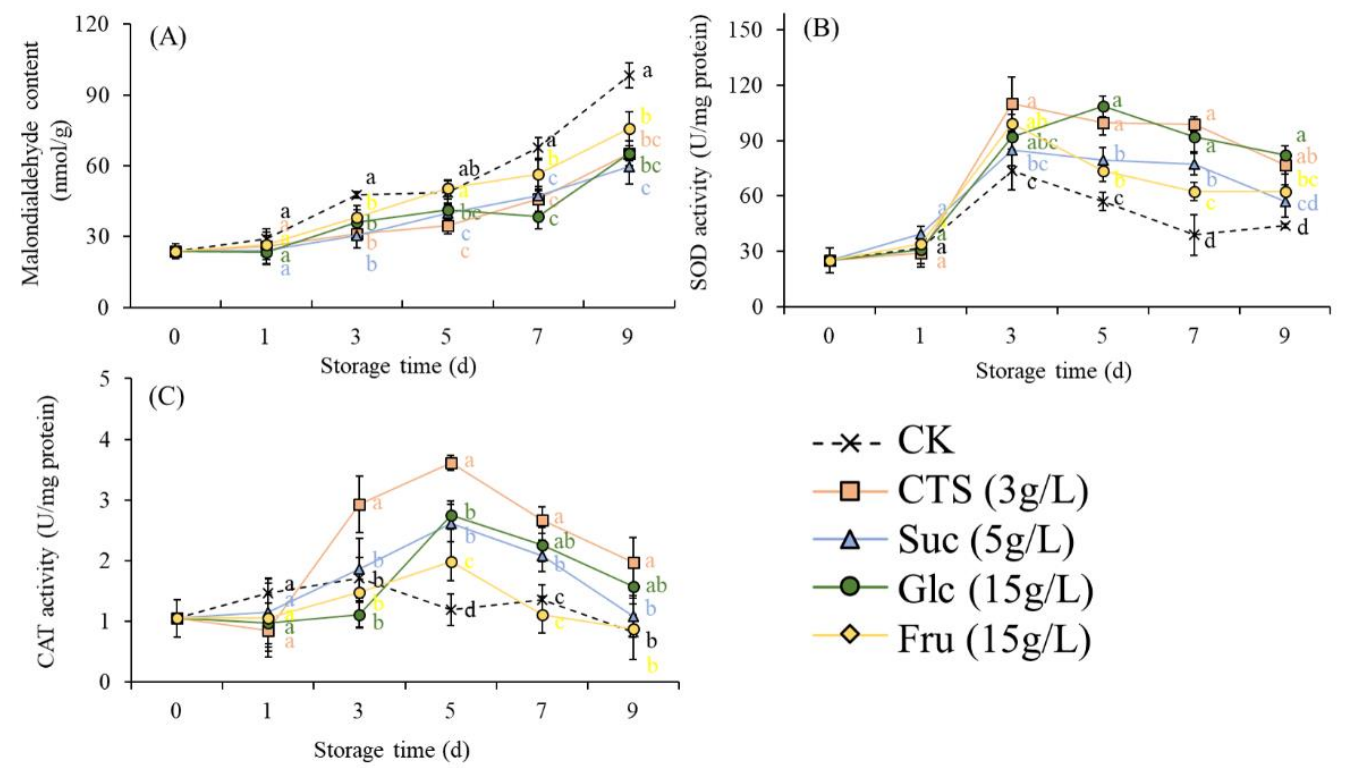

Figure 7. Effects of chitosan ( $3 \mathrm{~g} / \mathrm{L})$, sucrose $(5 \mathrm{~g} / \mathrm{L})$, glucose $(15 \mathrm{~g} / \mathrm{L})$, and fructose $(15 \mathrm{~g} / \mathrm{L})$ on the (A) malondialdehyde content, (B) SOD activity, and (C) CAT activity of strawberry fruits stored at $15 \pm 2{ }^{\circ} \mathrm{C}$ for $9 \mathrm{~d}$. CK represents that strawberry fruits were immersed with water before storage. Data are mean of three replicates. Different letters in the same storage time indicate a significant difference (Tukey's HSD test, $p<0.05$ ). CTS, chitosan; Suc, sucrose; Glc, glucose; Fru, fructose; SOD, superoxide dismutase; CAT, catalase.

\subsection{Effects of Treatments on the Expression of Genes Related to Fruit Senescence, Quality, and Disease Resistance}

Exogenous sugar treatment regulates the expression of a series of genes related to the ripening, metabolism, and disease resistance of harvested strawberries, and gene expression patterns differ depending on the sugar treatment used. Over time, the expression of sugar-related genes FaSUS1, FaSPS1, and FaSPS2 in all treatment groups first increased and then decreased (Figure 8). On day 3, the expression of acidity-related genes FaCS1 and $\mathrm{FaCS} 2$ in the chitosan and glucose groups declined sharply, whereas the expression of FaMDH1 and FaMDH2 increased notably (Figure 8). On the same day, the expression of $\mathrm{FaCS} 1$ and $\mathrm{FaCS} 2$ in the sucrose and fructose groups increased notably (Figure 8). On day 5, however, the expression of FaCS1 and FaCS2 decreased sharply. On day 3, the expression of FaMDH1 and FaMDH2 in the sucrose and fructose groups declined sharply, and on day 9, the expression of $\mathrm{FaMDH} 2$ in the chitosan, sucrose, and glucose groups decreased significantly (Figure 8). During storage, the expression of aroma-related genes $F a Q R$ and $F a E O B I I$ in all treatment groups first increased and then decreased (Figure 8). The expression levels of FaEXP1 and FaEXP3 in the chitosan and glucose groups clearly decreased starting from day 5 (Figure 8). In the sucrose and fructose groups, the expression levels of FaEXP1 increased considerably starting from day 5. During storage, the expression levels of $F a M Y B 1$ in the chitosan group first decreased and then increased, reaching their minimum on day 3 (Figure 8). By contrast, the expression levels of FaMYB1 in the sucrose, glucose, and fructose groups first increased and then decreased, peaking on day 3 . The expression of FaMYB10 in all treatment groups was significantly downregulated in the late storage period (Figure 8).

Strawberries are easily damaged by pathogenic bacteria after being harvested, resulting in decay and deterioration. As signaling molecules, hormones play a vital role in regulating fruit senescence and disease resistance. Therefore, we investigated changes in the expression of key genes in the JA and ABA signaling pathways in each treatment group. The expression of FaJAZ1 in the sucrose and fructose groups first decreased and then increased, whereas that in the chitosan and glucose groups first increased and then decreased (Figure 8). In the sucrose and fructose groups, the expression of FaJAZ2 was 
significantly downregulated, but it was significantly upregulated on day 9 (Figure 8). In the chitosan and glucose groups, $\mathrm{FaOPR} 3$ expression first increased and then decreased (Figure 8). By contrast, FaOPR3 expression first decreased and then increased in the sucrose and fructose groups. The expression of FaNCED1 and FaNCED2 also changed notably during storage (Figure 8). Starting from day 5, the expression of FaNCED1 in all treatment groups increased substantially. On day 3, FaNCED2 expression decreased significantly in the chitosan and glucose groups and increased significantly in the sucrose and fructose groups. During storage, the expression of polygalacturonase-inhibiting protein (PGIP) 1 and PGIP2 as well as WRKY1, WRKY33, and WRKY70 (transcription factors related to disease resistance in strawberries) were regulated to varying extents. In the early stage of storage, FaPGIP1, FaWRKY1, and FaWRKY 33 expression was significantly elevated in the chitosan and glucose groups but decreased significantly on day 9 (Figure 8). In the chitosan and sucrose groups, FaWRKY70 expression decreased significantly from day 7 (Figure 8).

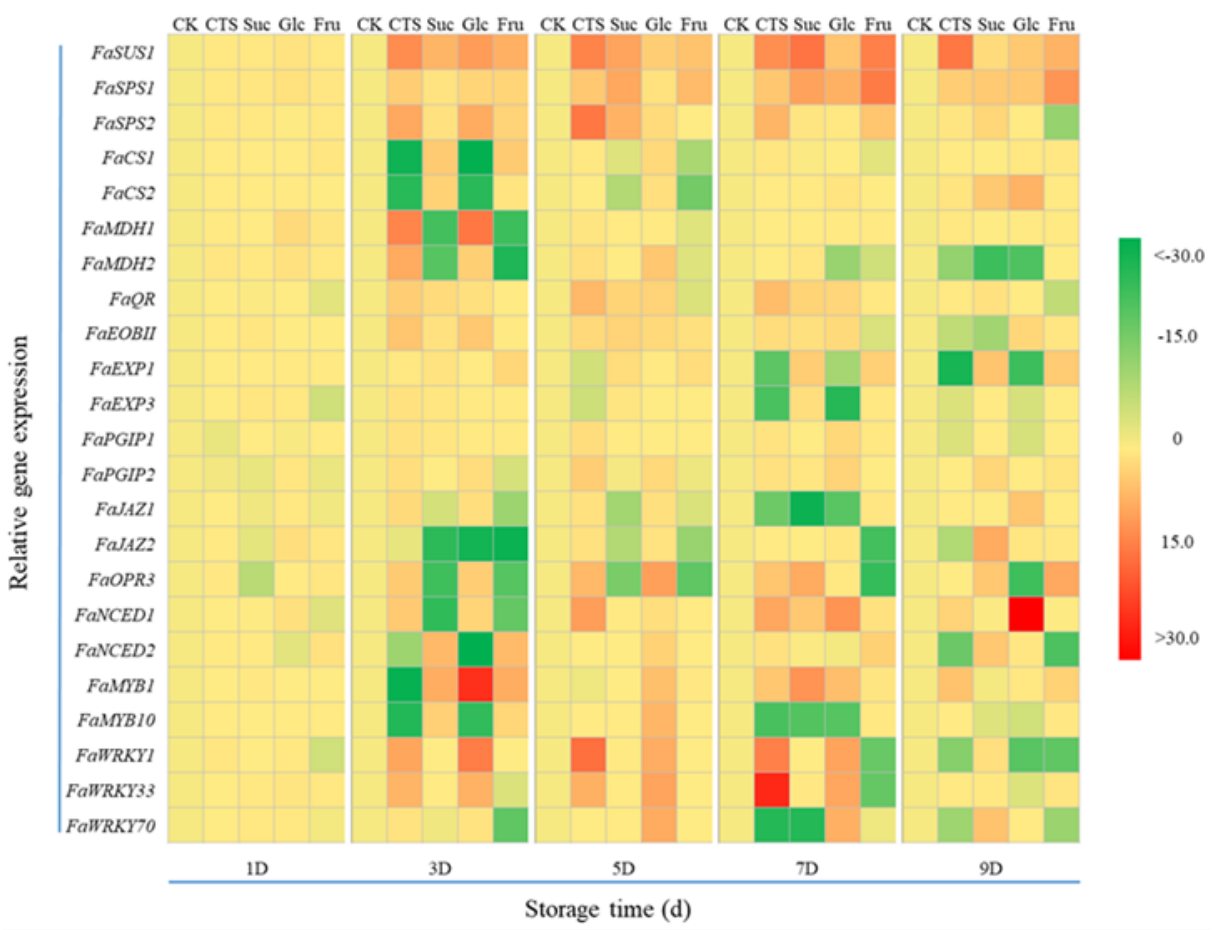

Figure 8. Effects of chitosan ( $3 \mathrm{~g} / \mathrm{L})$, sucrose $(5 \mathrm{~g} / \mathrm{L})$, glucose $(15 \mathrm{~g} / \mathrm{L})$, and fructose $(15 \mathrm{~g} / \mathrm{L})$ on transcription of genes related to fruit quality and disease resistance. The fruit treated with distilled water was used as the control (CK), relative gene expressions in strawberries treated with $3 \mathrm{~g} / \mathrm{L}$ chitosan, $5 \mathrm{~g} / \mathrm{L}$ sucrose, $15 \mathrm{~g} / \mathrm{L}$ glucose, and $15 \mathrm{~g} / \mathrm{L}$ fructose were calculated. The expressions in the chitosan, sucrose, glucose, and fructose groups were then each divided by that in the control, and the results were used to create a heat map. CTS, chitosan; Suc, sucrose; Glc, glucose; Fru, fructose.

\section{Discussion}

The decay index is a key parameter when assessing the freshness of fruits and vegetables in storage. Respiration and transpiration can contribute to weight loss (i.e., loss of water content) in harvested fruit and affect its quality. In all strawberries treated in this study, the decay index and weight loss were reduced and the commodity rate was increased (Figures 3 and 4; Table 1). These results are in line with other reports. Patel and Panigrahi [35] observed that coating harvested cucumbers with a starch-glucose mixture substantially reduced weight loss, maintained high levels of soluble sugars and proteins, and preserved highly active antioxidases. The treatment extended the shelf life of the cucumbers from 7 to 30 days. Postharvest treatment with $5 \mathrm{~g} / \mathrm{L}$ chitosan is effective for the prevention and control of gray mold in Kiwifruit [36]. Broccoli treated with a $12 \mathrm{~g} / \mathrm{L}$ sucrose solution exhibited delayed chlorophyll degradation, increased antioxidant levels 
and antioxidase activity, and slower senescence and chlorosis during storage [23]. In the present study, treatment outcomes varied with the type of sugar used, with chitosan yielding the optimal results. Specifically, at the end of the storage period, the chitosan group had the lowest overall decay index and weight loss (Figure 4; Table 1). This is attributable to the antioxidative and antimicrobial properties of chitosan; the formation of a thin, semipermeable polymer film on the strawberries' surface reduced evaporation and prevented exposure to air. Other studies have suggested that chitosan coatings are effective in reducing the respiration rate of and loss of moisture from harvested fruit [28,37]. This study presents new evidence to support the premise that chitosan is effective in suppressing disease development in harvested fruits and vegetables [38,39]. Given that firmness is a crucial parameter indicative of strawberries' degree of senescence, its maintenance during storage is essential. By the end of the storage period, the strawberries in the control group had clearly lost their firmness and become relatively mushy (Table 1). The strawberries treated with chitosan, sucrose, or glucose solution were firmer than were those in the control group, and the firmness of glucose group was significantly higher than that of the control group (Table 1). These results demonstrated that sugar helped maintain the fruits' firmness during storage. Chen et al. [40] discovered that the firmness of strawberries increases during the early period of storage, probably because of loss of water from the surface of the fruit. As strawberries ripen, they turn from green to pink or red and finally to dark red. In the present study, changes in the color and luster of strawberries were evaluated by examining $a^{*}$ and $L^{*}$ values. At the end of the storage period, the $a^{*}$ values in all groups were substantially higher than they were upon harvest, whereas the $\mathrm{L}^{*}$ values were all obviously lower than they were upon harvest (Table 1). This indicated that the strawberries were postmature, which contributes to browning and loss of luster. The $\mathrm{L}^{*}$ values of the glucose-treated strawberries were significantly higher than those of the control group (Table 1), suggesting that glucose inhibited browning and helped maintain color and luster. Siebeneichler et al., found that sucrose treatment had a negligible effect on the luster of strawberries [5], similar to our results. Sensory evaluation is the most intuitive method for assessing the freshness of harvested strawberries. At the end of the storage period, the control group had the poorest scores for luster, firmness, and aroma (Figure 5). The production of undesirable brown or black pigment by polyphenol oxidases (PPOs) is responsible for the poor luster score [41]. Loss of water content increased the firmness. The loss of or change in volatile compounds implicated in the metabolism of strawberries in storage was also involved [22,40]. Moreover, the surfaces of some strawberries in the control group exhibited mold spots and liquid from fruit rot at the end of the storage period (Figure 5). This indicated a complete loss of commercial value. The chitosan and glucose groups scored well in the sensory evaluation (Figure 5), demonstrating that freshness was favorably preserved in these groups.

The taste of strawberries depends on their TSS and TA. Thus, strawberries' maturation stage and quality can be assessed by measuring changes in these levels during storage [42]. Herein, TSS levels in all groups first increased and then decreased during the storage period (Figure 6A). These fluctuations may have been associated with TSS production through the decomposition of carbohydrate, as well as with TSS consumption for respiration [31]. Transpiration was another contributor to the increase in TSS through the loss of water [27]. Similarly, Hassan et al. reported that the TSS content of harvested strawberries tended to first increase and then decrease over time [43]. In a study by Nie et al. [44], the TSS content of the pulp of harvested pomelos dropped sharply over time, and the TSS content of pomelo pulp treated with exogenous chitosan was significantly higher than that in the blank control. Patel and Panigrahi [35] noted that the application of a starch-glucose coating helped maintain high TSS content of harvested cucumbers and extended their shelf life. In this study, the TA declined in all groups during the storage period; however, this reduction was, to varying degrees, inhibited by the treatments (Figure 6B). This observation is consistent with the results obtained by Bal and Ürün [45]. The reduction in TA during the late storage period is potentially attributable to the consumption of titratable acid as a substrate for 
the respiratory process of the strawberries [46]. Anthocyanin is a secondary metabolite that crucially affects the appearance of fruit during postharvest storage [47]. In this study, the TAC in all groups increased gradually in the early storage period (Figure 6C). This accords with previous reports $[28,37]$ and can probably be explained by the continued synthesis of anthocyanins in harvested strawberries through flavonoid and anthocyanin pathways $[28,48]$. In the late storage period, the TAC decreased considerably in all groups (Figure 6C). This was probably due to the water loss-induced degradation of anthocyanin and to the increased activity of PPOs in the strawberries, which triggered a physiological stress response that promoted senescence $[38,49,50]$. At the end of the storage period, the TAC was significantly higher in the chitosan, sucrose, glucose, and fructose groups than in the control group (Figure 6C). This was probably because the chitosan layer protected the strawberries from exposure to air, thereby inhibiting the oxidation of anthocyanin. By contrast, exposure to sucrose induced anthocyanin production in the strawberries [5].

MDA, one of the main products derived from peroxidation of cell membranes, is often used for the assessment of cellular oxidative damage in plant tissues [33]. Herein, the MDA levels in all groups increased gradually over time; at the end of the storage period, the MDA levels in the chitosan, glucose, fructose, and sucrose groups were significantly lower than those in the control group (Figure 7A). For the chitosan group, this could be attributable to the formation of a semipermeable barrier by chitosan on the surface of the strawberries to reduce oxygen intake and carbon dioxide emission, thereby providing a favorable gaseous environment for freshness preservation and alleviating oxidative damage [51]. Nguyen and Nguyen [52] reported similar findings in 2020. Studies have demonstrated that in strawberries, exogenous sucrose acts on ABA synthesis to regulate the production of antioxidants such as anthocyanin and vitamin $C[5,53]$. Herein, the TAC was significantly higher in the sucrose group, suggesting a potential association between exposure to sucrose and enhanced antioxidant activity in strawberries (Figure 6C). Pareek [54] found that exogenous calcium could help delay senescence in plant tissues by triggering the accumulation of ascorbic acid and other antioxidants. Changes in the level of vitamin $C$ in the treatment groups were not examined in the present study. Appropriate techniques for freshness preservation inhibit the postharvest drop in antioxidant levels, increase antioxidase activity, and enhance the free-radical-scavenging activities of fruits and vegetables $[18,55,56]$. This both delays senescence and enriches their nutritional value. SOD and CAT are two essential endogenous enzymes that act against oxidative damage. A frontline enzymatic antioxidant in the reactive oxygen species (ROS) scavenging system, SOD is capable of eliminating excessive $\mathrm{O}_{2}{ }^{-}$in organisms by converting it into nontoxic $\mathrm{O}_{2}$ and less toxic $\mathrm{H}_{2} \mathrm{O}_{2}$ [57]. CAT enables the conversion of $\mathrm{H}_{2} \mathrm{O}_{2}$ into $\mathrm{H}_{2} \mathrm{O}$ to prevent $\mathrm{H}_{2} \mathrm{O}_{2}$-induced cell damage [58]. In the present study, enhanced metabolism of tissues and cells was observed in all groups over time, as was increased production of ROS. However, increased SOD and CAT activities in the treatment groups, especially the chitosan and glucose groups (Figure 7B,C), delayed senescence by establishing a balance between ROS production and elimination. During the late storage period, water loss and decay were observed in postmature fruit. SOD and CAT activity were inhibited (Figure 7B,C), and the ROS scavenging system became less effective, resulting in ROS accumulation. This in turn accelerated senescence. These findings accord with those of previous studies $[44,59,60]$.

To further understand the roles and molecular mechanisms of sugars in the physiology and disease resistance of harvested strawberries, we detected during storage the expression of genes involved in ripening, senescence, and disease resistance. Expression of genes involved in sucrose metabolism [61], including the sucrose synthase gene $F a$ SUS1 and sucrose phosphate synthase genes FaSUS1 and FaSUS2, first increased and then decreased over time in all treatment groups (Figure 8). This indicated that the strawberries' sucrose metabolism pathways were initially oriented toward synthesis and gradually shifted toward decomposition. The results suggest that the sugar treatments improved the strawberries' disease resistance and delayed their senescence by causing the synthesis of considerable sucrose in the early stage of storage [31]. In the late stage, as metabolic 
processes became more active, a large amount of sugar-converted acid was consumed as a respiratory substrate, resulting in a reduction in sugar content. Malic acid and citric acid participate in the tricarboxylic acid cycle of plant cells and have physiological importance for the metabolism of glucose, fat, and protein in plants [62]. With extension of the storage period, malate dehydrogenase genes FaMDH1 and FaMDH2 and citrate synthase genes FaCS1 and FaCS2 were regulated to varying degrees in the treatment groups (Figure 8). Overall, the sugar treatments may improve the disease resistance of strawberries and delay their senescence by regulating the dynamic balance of malic acid content and citric acid content [63]. In the late stage of storage, the TA content decreased significantly in all the treatment groups (Figure 6B). This may have been due to an increase in respiratory metabolism; conversely, it may have been due to downregulation of FaMDH1, FaMDH2, $\mathrm{FaCS1}$, and FaCS2 (Figure 8), which would reduce the activities of malate dehydrogenase and citrate synthase and subsequently reduce the accumulation of TA. Consistent with the sensory evaluation results, the expression of aroma-related genes FaQR and FaEOBII in all treatment groups first increased and then decreased (Figure 8). This may have been because the fruits further matured in the early stage of storage, whereas in the late stage, senescence led to changes in the amounts of metabolism-related volatile compounds.

Expansion (Exp) is a protein that regulates the relaxation and extension of plant cell walls. It also plays a pivotal role in fruit ripening and softening. Exp has been confirmed to be related to ripening and softening in tomatoes [64], loquats [65], and strawberries [25] among other fruits. In the late stage of storage, the expression of FaEXP1 and FaEXP3 in the chitosan and glucose groups was significantly downregulated, indicating that the strawberries' cell walls had degraded through aging (Figure 8). Myb proteins are the most widely regulated factor in the anthocyanin biosynthesis pathway in plants. Myb1 and Myb10 have been demonstrated to regulate anthocyanin synthesis in grapes [26], gerbera hybrida [66], and nectarines [67]. In the present study, FaMYB1 expression in all treatment groups first increased and then decreased, and FaMYB10 expression decreased significantly during the late stage of storage (Figure 8). These results were in line with the TAC results in strawberry fruits (Figure 6C). This indicated that the strawberries continued to synthesize anthocyanins in the early stage of storage, and that in the late stage, anthocyanins were degraded due to water loss and the increase in PPO content. In the early stage of storage, FaMYB1 was upregulated slightly later in the chitosan group compared with in the other treatment groups (Figure 8). This may have been because chitosan formed a protective film on the fruit surface, thereby reducing respiration and delaying further maturation. Numerous studies have confirmed that plant hormones JA and ABA participate in immune signaling networks and regulate disease resistance $[39,68,69]$. Over time, genes related to the anabolic JA and ABA pathways (e.g., FaJAZ1, FaJAZ2, FaOPR3, FaNCED1, and FaNCED2) in the treatment groups were regulated to varying degrees (Figure 8). Overall, the results indicate that sugar treatments regulate strawberries' senescence and disease resistance by acting on hormone signaling networks. PGIPs and pathogenesis-related proteins also contribute critically to disease development and necrosis in plants [70]. In this study, expression of FaPGIP1, FaWRKY1, and FaWRKY33 was significantly upregulated in the chitosan and glucose groups in the early stage of storage but then decreased significantly at the end of the storage period (Figure 8). This indicates that sugar treatment delays senescence in strawberries and strengthens their disease resistance by upregulating the expression of PGIP and WRKY genes.

As a biodegradable, eco-friendly and edible coating, chitosan has been implicated in fruit preservation to reduce moisture loss and microbial growth and thus retain postharvest quality [71]. Moreover, glucose has been combined with $\beta$-D-glucose oxygen 1oxidoreductase to prevent $B$. cinerea growth on postharvest strawberry fruit [10]. Our results show that chitosan and glucose had positive effect on strawberries preservation, suggesting chitosan and glucose could be a promising inhibitors to effectively control fungal growth in postharvest strawberry fruit. However, the effect of sugars on spoilage associate bacterial and fungal contaminants is not examined in the current study, and fur- 
ther studies need to be conducted. Additionally, further exploration needs to be done to understand the mechanism of sugar against pathogens on postharvest fruits at the molecular level.

\section{Conclusions}

The results indicate that immersion in sugar solutions is a potentially useful treatment for extending strawberries' shelf life. Compared with immersion in distilled water, immersion in chitosan or glucose solution inhibited decay, retained firmness, and controlled weight loss in strawberries. Moreover, these treatments conferred benefits in terms of TSS, TA, TAC, and antioxidant enzyme capacities. Immersing in $3 \mathrm{~g} / \mathrm{L}$ chitosan or $15 \mathrm{~g} / \mathrm{L}$ glucose solution may delay senescence in harvested strawberries by regulating the sugar-acid ratio, the production of antioxidant substances, and antioxidant enzyme activity. The findings also suggest that exogenous chitosan or glucose improves the fruit's disease resistance by regulating the expression of genes related to disease resistance and hormones in harvested strawberries.

Supplementary Materials: The following are available online at https://www.mdpi.com/article/10 .3390 /horticulturae7120518/s1, Figure S1: Schematic diagram of changes in fruit color and luster during storage, Table S1: Sensory evaluation indicator and evaluation standard of strawberry, Table S2: Primers used for gene expression analysis by qRT-PCR.

Author Contributions: Conceptualization, Y.W. and G.Z.; methodology, Y.W., G.Z. and B.L.; validation, Q.Z. and Q.L.; investigation, Y.W., W.T. and G.Z.; writing-original draft preparation, Y.W. and G.Z.; writing-review and editing, Z.Y. and W.T. All authors have read and agreed to the published version of the manuscript.

Funding: This research was supported by the Natural Science Foundation of Jiangsu Province, China, BK20211125; the Science Fund of Jiangsu Vocational College of Agriculture and Forestry, 2019kj011, 2020kj057; Six Talent Peaks Project in Jiangsu Province, NY-156; Blue Project of Jiangsu Province; Zhenjiang Science \& Technology Program, NY2020015; Innovation Training Program for College Students of Jiangsu Vocational College of Agriculture and Forestry, 202113103005y.

Data Availability Statement: The data presented in this study are available on request from the corresponding author.

Conflicts of Interest: The authors declare no conflict of interest.

\section{References}

1. Campaniello, D.; Bevilacqua, A.; Sinigaglia, M.; Corbo, M.R. Chitosan: Antimicrobial activity and potential applications for preserving minimally processed strawberries. Food Microbiol. 2008, 25, 992-1000. [CrossRef]

2. Yosefi, A.; Mozafari, A.; Javadi, T. Jasmonic acid improved in vitro strawberry (Fragaria $\times$ ananassa Duch.) resistance to PEGinduced water stress. Plant Cell Tiss. Organ. Cult. 2020, 142, 549-558. [CrossRef]

3. Blanch, M.; Goñi, O.; Sanchez-Ballesta, M.T.; Escribano, M.I.; Merodio, C. Characterisation and functionality of fructooligosaccharides affecting water status of strawberry fruit (Fragraria vesca cv. Mara de Bois) during postharvest storage. Food Chem. 2012, 134, 912-919. [CrossRef]

4. Liu, C.; Zheng, H.; Sheng, K.; Liu, W.; Zheng, L. Effects of melatonin treatment on the postharvest quality of strawberry fruit. Postharvest Biol. Technol. 2018, 139, 47-55. [CrossRef]

5. Siebeneichler, T.J.; Crizel, R.L.; Camozatto, G.H.; Paim, B.T.; Messias, R.S.; Rombaldi, C.V.; Galli, V. The postharvest ripening of strawberry fruits induced by abscisic acid and sucrose differs from their in vivo ripening. Food Chem. 2020, 317, 126407. [CrossRef]

6. Vighi, I.L.; Crizel, R.L.; Perin, E.C.; Rombaldi, C.V.; Galli, V. Crosstalk during fruit ripening and stress response among abscisic acid, calcium-dependent protein kinase and phenylpropanoid. Crit. Rev. Plant Sci. 2019, 38, 99-116. [CrossRef]

7. Sallato, B.V.; Torres, R.; Zoffoli, J.P.; Latorre, B.A. Effect of boscalid on postharvest decay of strawberry caused by Botrytis cinerea and Rhizopus stolonifer. Span. J. Agric. Res. 2007, 5, 67-78. [CrossRef]

8. Osorio, L.F.; Pattison, J.A.; Peres, N.A.; Whitaker, V.M. Genetic variation and gains in resistance of strawberry to Colletotrichum gloeosporioides. Phytopathology 2014, 104, 67. [CrossRef]

9. Cagnon, T.; Méry, A.; Chalier, P.; Guillaume, C.; Gontard, N. Fresh food packaging design: A requirement driven approach applied to strawberries and agro-based materials. Innov. Food Sci. Emerg. Technol. 2013, 20, 288-298. [CrossRef]

10. Li, X.; Xie, X.; Xing, F.; Xu, L.; Zhang, J.; Wang, Z. Glucose oxidase as a control agent against the fungal pathogen Botrytis cinerea in postharvest strawberry. Food Control 2019, 105, 277-284. [CrossRef] 
11. Petrasch, S.; Knapp, S.J.; van Kan, J.A.L.; Blanco-Ulate, B. Grey mould of strawberry, a devastating disease caused by the ubiquitous necrotrophic fungal pathogen Botrytis cinerea. Mol. Plant Pathol. 2019, 20, 877-892. [CrossRef] [PubMed]

12. Sellitto, V.M.; Zara, S.; Fracchetti, F.; Capozzi, V.; Nardi, T. Microbial biocontrol as an alternative to synthetic fungicides: Boundaries between pre- and postharvest applications on vegetables and fruits. Fermentation 2021, 7, 60. [CrossRef]

13. Han, C.; Zhao, Y.; Leonard, S.W.; Traber, M.G. Edible coatings to improve storability and enhance nutritional value of fresh and frozen strawberries (Fragaria $\times$ ananassa) and raspberries (Rubus ideaus). Postharvest Biol. Technol. 2004, 33, 67-78. [CrossRef]

14. Chen, C.; Zhang, H.; Dong, C.; Ji, H.; Zhang, X.; Li, L.; Ban, Z.; Zhang, N.; Xue, W. Effect of ozone treatment on the phenylpropanoid biosynthesis of postharvest strawberries. RSC Adv. 2019, 9, 25429. [CrossRef]

15. Civello, P.M.; Martínez, G.A.; Chaves, A.R.; Añón, M.C. Heat treatments delay ripening and postharvest decay of strawberry fruit. J. Agric. Food Chem. 1997, 45, 4589-4594. [CrossRef]

16. Chen, C.; Cao, Z.; Li, J.; Tao, C.; Feng, Y.; Han, Y. A novel endophytic strain of Lactobacillus plantarum CM-3 with antagonistic activity against Botrytis cinerea on strawberry fruit. Biol. Control 2020, 148, 104306. [CrossRef]

17. He, Y.; Bose, S.K.; Wang, M.; Li, T.; Wang, W.; Lu, H.; Yin, H. Effects of chitosan oligosaccharides postharvest treatment on the quality and ripening related gene expression of cultivated strawberry fruits. J. Berry Res. 2018, 9, 1-16. [CrossRef]

18. El-Mogy, M.M.; Ali, M.R.; Darwish, O.S.; Rogers, H.J. Impact of salicylic acid, abscisic acid, and methyl jamonate on postharvest quality and bioactive compounds of cultivated strawberry fruit. J. Berry Res. 2019, 9, 333-348. [CrossRef]

19. Zhao, J.; Pan, L.; Zhou, M.; Yang, Z.; Meng, Y.; Zhang, X. Comparative physiological and transcriptomic analyses reveal mechanisms of improved osmotic stress tolerance in annual ryegrass by exogenous chitosan. Genes 2019, 10, 853. [CrossRef]

20. Pongprayoon, W.; Roytrakul, S.; Pichayangkura, R.; Chadchawan, S. The role of hydrogen peroxide in chitosan-induced resistance to osmotic stress in rice (Oryza sativa L.). Plant Growth Regul. 2013, 70, 159-173. [CrossRef]

21. Virgen-Ortiz, J.J.; Morales-Ventura, J.M.; Colín-Chávez, C.; Esquivel-Chávez, F.; Vargas-Arispuro, I.; Aispuro-Hernández, E.; Martínez-Téllez, M.A. Postharvest application of pectic-oligosaccharides on quality attributes, activities of defense-related enzymes, and anthocyanin accumulation in strawberry. J. Sci. Food Agric. 2020, 100, 1949-1961. [CrossRef] [PubMed]

22. Badawy, M.E.I.; Rabea, E.I.; El-Nouby, M.A.M.; Ismail, R.I.A.; Taktak, N.E.M. Strawberry shelf life, composition, and enzymes activity in response to edible chitosan coatings. Int. J. Fruit Sci. 2017, 17, 117-136. [CrossRef]

23. Xu, F.; Tang, Y.; Dong, S.; Shao, X.; Wang, H.; Zheng, Y.; Yang, Z. Reducing yellowing and enhancing antioxidant capacity of broccoli in storage by sucrose treatment. Postharvest Biol. Technol. 2016, 112, 39-45. [CrossRef]

24. Fei, L.; Yuan, X.; Chen, C.; Wan, C.; Fu, Y.; Chen, J.; Gan, Z. Exogenous Application of Sucrose Promotes Postharvest Ripening of Kiwifruit. Agronomy 2020, 10, 245. [CrossRef]

25. Molinett, S.A.; Alfaro, J.F.; Sáez, F.A.; Elgueta, S.; Moya-León, M.A.; Figueroa, C.R. Postharvest treatment of hydrogen sulfide delays the softening of chilean strawberry fruit by downregulating the expression of key genes involved in pectin catabolism. Int. J. Mol. Sci. 2021, 22, 10008. [CrossRef]

26. Kobayashi, S.; Goto-Yamamoto, N.; Hirochika, H. Retrotransposon-induced mutations in grape skin color. Science 2004, $304,982$. [CrossRef]

27. Hernández-Muñoz, P.; Almenar, E.; Del Valle, V.; Velez, D.; Gavara, R. Effect of chitosan coating combined with postharvest calcium treatment on strawberry (Fragaria $\times$ ananassa) quality during refrigerated storage. Food Chem. 2008, 110, 428-435. [CrossRef]

28. Nguyen, V.; Nguyen, D.; Nguyn, H. Combination effects of calcium chloride and nano-chitosan on the postharvest quality of strawberry (Fragaria $\times$ ananassa duch.). Postharvest Biol. Technol. 2020, 162, 111103. [CrossRef]

29. Lu, H.; Wang, K.; Wang, L.; Li, D.; Yan, J.; Ban, Z.; Luo, Z.; Li, L.; Yang, D. Effect of superatmospheric oxygen exposure on strawberry (Fragaria $\times$ ananassa Fuch.) volatiles, sensory and chemical attributes. Postharvest Biol. Technol. 2018, 142, 60-71. [CrossRef]

30. Vieira, J.M.; Flores-López, M.L.; de Rodríguez, D.J.; Sousa, M.C.; Vicente, A.A.; Martins, J.T. Effect of chitosan-Aloe vera coating on postharvest quality of blueberry (Vaccinium corymbosum) Fruit. Postharvest Biol. Technol. 2016, 116, 88-97. [CrossRef]

31. Xing, Y.; Yang, S.; Xu, Q.; Xu, L.; Zhu, D.; Li, X.; Shui, Y.; Liu, X.; Bi, X. Effect of chitosan/nano-TiO 2 composite coating on the postharvest quality of blueberry fruit. Coatings 2021, 11, 512. [CrossRef]

32. Heath, R.L.; Packer, L. Photoperoxidation in isolated chloroplasts: I. Kinetics and stoichiometry of fatty acid peroxidation. Arch. Biochem. Biophys. 1968, 125, 189-198. [CrossRef]

33. Zhang, G.; Wang, Y.; Wu, K.; Zhang, Q.; Feng, Y.; Miao, Y.; Yan, Z. Exogenous application of chitosan alleviate salinity stress in lettuce (Lactuca sativa L.). Horticulturae 2021, 7, 342. [CrossRef]

34. Bradford, M.M. A rapid and sensitive method for the quantitation of microgram quantities of protein utilizing the principaldye binding. Anal. Biochem. 1976, 72, 248-254. [CrossRef]

35. Patel, C.; Panigrahi, J. Starch glucose coating-induced postharvest shelf-life extension of cucumber. Food Chem. 2019, 288, 208-214. [CrossRef]

36. Zheng, F.; Zheng, W.; Li, L.; Pan, S.; Liu, M.; Zhang, W.; Liu, H.; Zhu, C. Chitosan controls postharvest decay and elicits defense response in kiwifruit. Food Bioproc. Technol. 2017, 10, 1937-1945. [CrossRef]

37. Gol, N.B.; Patel, P.R.; Rao, T.R. Improvement of quality and shelf-life of strawberries with edible coatings enriched with chitosan. Postharvest Biol. Technol. 2013, 85, 185-195. [CrossRef] 
38. Eshghi, S.; Hashemi, M.; Mohammadi, A.; Badii, F.; Mohammadhoseini, Z.; Ahmadi, K. Effect of nanochitosan-based coating with and without copper loaded on physicochemical and bioactive components of fresh strawberry fruit (Fragaria $\times$ ananassa Duchesne) during storage. Food Bioproc. Technol. 2014, 7, 2397-2409. [CrossRef]

39. Zhang, P.; Jia, H.; Gong, P.; Sadeghnezhad, E.; Pang, Q.; Dong, T.; Li, T.; Jin, H.; Fang, J. Chitosan induces jasmonic acid production leading to resistance of ripened fruit against botrytis cinerea infection. Food Chem. 2021, 337, 127772.

40. Chen, F.; Liu, H.; Yang, H.; Lai, S.; Cheng, X.; Xin, Y.; Yang, B.; Hou, H.; Yao, Y.; Zhang, S.; et al. Quality attributes and cell wall properties of strawberries (Fragaria annanassa Duch.) under calcium chloride treatment. Food Chem. 2011, 126, 450-459. [CrossRef]

41. Chisari, M.; Barbagallo, R.N.; Spagna, G. Characterization of polyphenol oxidase and peroxidase and influence on browning of cold stored strawberry fruit. J. Agric. Food Chem. 2007, 55, 3469-3476. [CrossRef] [PubMed]

42. Benítez, S.; Soro, L.; Achaerandio, I.; Sepulcre, F.; Pujolà, M. Combined effect of a low permeable film and edible coatings or calcium dips on the quality of fresh-cut pineapple. J. Food Process. Eng. 2014, 37, 91-99. [CrossRef]

43. Hassan, J.; Anwar, R.; Khan, A.S.; Ahmad, S.; Malik, A.U.; Nafees, M.; Hussain, Z.; Inam-ur-Raheem, M. Chitosan-based edible coating delays fungal decay and maintains quality of strawberries during storage. Intl. J. Agric. Biol. 2020, $24,486-492$.

44. Nie, Z.; Huang, Q.; Chen, C.; Wan, C.; Chen, J. Chitosan coating alleviates postharvest juice sac granulation by mitigating ROS accumulation in harvested pummelo (Citrus grandis L. Osbeck) during room temperature storage. Postharvest Biol. Technol. 2020, 169, 111309. [CrossRef]

45. Bal, E.; Bahtiyar, A.Ü. Effects of chitosan coating with putrescine on bioactive compounds and quality of strawberry cv. san andreas during cold storage. Erwerbs-Obstbau 2021, 63, 1-8. [CrossRef]

46. Sogvar, O.B.; Saba, M.K.; Emamifar, A. Aloe vera and ascorbic acid coatings maintain postharvest quality and reduce microbial load of strawberry fruit. Postharvest Biol. Technol. 2016, 114, 29-35. [CrossRef]

47. Li, Z.; Wei, Y.; Xu, Y.; Han, P.; Jiang, S.; Xu, F.; Wang, H.; Tao, N.; Shao, X. Terpinen-4-ol treatment maintains quality of strawberry fruit during storage by regulating sucrose-induced anthocyanin accumulation. Postharvest Biol. Technol. 2021, $174,111461$. [CrossRef]

48. Kalt, W.; Forney, C.F.; Martin, A.; Prior, R.L. Antioxidant capacity, vitamin C, phenolics, and anthocyanins after fresh storage of small fruit. J. Agric. Food Chem. 1999, 47, 4638-4644. [CrossRef]

49. Nunes, M.C.N.; Brecht, J.K.; Morais, A.M.B.; Sargent, S.A. Possible influences of water loss and polyphenol oxidase activity on anthocyanin content and discoloration in fresh ripe strawberry (cv. Oso Grande) during storage at $1{ }^{\circ} \mathrm{C}$. J. Food Sci. 2005, 70, S79-S84. [CrossRef]

50. Ben-Yehoshua, S.; Rodov, V. Transpiration and water stress. Postharvest Physiol. Pathol. Veg. 2003, 2, 111-159.

51. Petriccione, M.; Mastrobuoni, F.; Pasquariello, M.S.; Zampella, L.; Nobis, E.; Capriolo, G.; Scortichini, M. Effect of chitosan coating on the postharvest quality and antioxidant enzyme system response of strawberry fruit during cold storage. Foods 2015, 4, 501-523. [CrossRef] [PubMed]

52. Nguyen, H.V.H.; Nguyen, D.H.H. Effects of nano-chitosan and chitosan coating on the postharvest quality, polyphenol oxidase activity and malondialdehyde content of strawberry (Fragaria $\times$ ananassa Duch.). J. Hort. Postharvest Res. 2020, 3, 11-24.

53. Jia, H.; Chai, Y.; Li, C.; Lu, D.; Luo, J.; Qin, L.; Shen, Y. Abscisic acid plays an important role in the regulation of strawberry fruit ripening. Plant Physiol. 2011, 157, 188-199. [CrossRef] [PubMed]

54. Pareek, S. Calcium treatments. In Novel Postharvest Treatments of Fresh Produce; CRC Press: Boca Raton, FL, USA, $2017 ;$ pp. 79-106.

55. Wang, S.Y.; Chen, C.S.; Yin, J.J. Effect of allyl isothiocyanate on antioxidants and fruit decay of blueberries. Food Chem. 2010, 120, 199-204. [CrossRef]

56. Safari, Z.S.; Ding, P.; Juju Nakasha, J.; Yusoff, S.F. Combining chitosan and vanillin to retain postharvest quality of tomato fruit during ambient temperature storage. Coatings 2020, 10, 1222. [CrossRef]

57. Apel, K.; Hirt, H. Reactive oxygen species: Metabolism, oxidative stress, and signal transduction. Annu. Rev. Plant Biol. 2004, 55, 373-399. [CrossRef]

58. Foyer, C.H.; Noctor, G. Oxidant and antioxidant signalling in plants: A re-evaluation of the concept of oxidative stress in a physiological context. Plant Cell Environ. 2005, 28, 1056-1071. [CrossRef]

59. Lu, H.; Ye, C.; Guo, S.; Sheng, K.; Shao, L.; Zhou, T.; Yu, T.; Zheng, X. Preharvest application of antagonistic yeast Rhodosporidium paludigenum induced resistance against postharvest diseases in mandarin orange. Biol. Control 2013, 67, 130-136. [CrossRef]

60. Petriccione, M.; Pagano, L.; Forniti, R.; Zampella, L.; Mastrobuoni, F.; Scortichini, M.; Mencarelli, F. Postharvest treatment with chitosan affects the antioxidant metabolism and quality of wine grape during partial dehydration. Postharvest Biol. Technol. 2018, 137, 38-45. [CrossRef]

61. Lastdrager, J.; Hanson, J.; Smeekens, S. Sugar signals and the control of plant growth and development. J. Exp. Bot. 2014, 65, 799-807. [CrossRef]

62. Shangguan, L.; Sun, X.; Zhang, C.; Mu, Q.; Leng, X.; Fang, J. Genome identification and analysis of genes encoding the key enzymes involved in organic acid biosynthesis pathway in apple, grape, and sweet orange. Sci. Hortic. 2015, 185, 22-28. [CrossRef]

63. Tang, N.; An, J.; Deng, W.; Gao, Y.; Chen, Z.; Li, Z. Metabolic and transcriptional regulatory mechanism associated with postharvest fruit ripening and senescence in cherry tomatoes. Postharvest Biol. Technol. 2020, 168, 111274. [CrossRef]

64. Rose, J.K.C.; Lee, H.H.; Bennett, A.B. Expression of a divergent expansin gene is fruit-specific and ripening-regulated. Proc. Natl. Acad. Sci. USA 1997, 94, 5955-5960. [CrossRef] 
65. Yang, S.; Sun, C.; Wang, P.; Shan, L.; Cai, C.; Zhang, B.; Zhang, W.; Li, X.; Ferguson, I.; Chen, K. Expression of expansin genes during postharvest lignification and softening of 'Luoyangqing' and 'Baisha' loquat fruit under different storage conditions. Postharvest Biol. Technol. 2008, 49, 46-53. [CrossRef]

66. Elomaa, P.; Uimari, A.; Mehto, M.; Albert, V.A.; Laitinen, R.A.E.; Teeri, T.H. Activation of anthocyanin biosynthesis in Gerbera hybrida (Asteraceae) suggests conserved protein-protein and protein-promoter interactions between the anciently diverged monocots and eudicots. Plant Physiol. 2003, 133, 1831-1842. [CrossRef] [PubMed]

67. Ravaglia, D.; Espley, R.V.; Henry-Kirk, R.A.; Andreotti, C.; Ziosi, V.; Hellens, R.P.; Costa, G.; Allan, A.C. Transcriptional regulation of flavonoid biosynthesis in nectarine (Prunus persica) by a set of R2R3 MYB transcription factors. BMC Plant Biol. 2013, 13, 68-81. [CrossRef]

68. Pieterse, C.M.; Van der Does, D.; Zamioudis, C.; Leon-Reyes, A.; Van Wees, S.C. Hormonal modulation of plant immunity. Annu. Rev. Cell Dev. Biol. 2012, 28, 489-521. [CrossRef] [PubMed]

69. Wang, Y.; Zhao, F.; Zhang, G.; Jia, S.; Yan, Z. FaWRKY11 transcription factor positively regulates resistance to Botrytis cinerea in strawberry fruit. Sci. Hortic. 2021, 279, 109893. [CrossRef]

70. Saavedra, G.M.; Sanfuentes, E.; Figueroa, P.M.; Figueroa, C.R. Independent preharvest applications of methyl jasmonate and chitosan elicit differential upregulation of defense-related genes with reduced incidence of gray mold decay during postharvest storage of Fragaria chiloensis fruit. Int. J. Mol. Sci. 2017, 18, 1420. [CrossRef]

71. Zhang, H.; Ge, L.; Chen, K.; Zhao, L.; Zhang, X. Enhanced biocontrol activity of Rhodotorula mucilaginosa cultured in media containing chitosan against postharvest diseases in strawberries: Possible mechanisms underlying the effect. J. Agric. Food Chem. 2014, 62, 4214-4224. [CrossRef] [PubMed] 